\title{
Melkersson Rosenthal syndrome: a case report of a rare disease
}

\section{Taysir Ben Achour, Sameh Sayhi}

Autoimmune Disease Research Unit (UR17DN02), Internal Department of Medicine, Military Hospital of Tunis, Tunisia

Corresponding author: Dr. Sameh Sayhi, E-mail: sameh_sayhi@yahoo.fr

Melkersson-Rosenthal syndrome (MRS) or Cheilitis granulomatosa is a rare granulomatous disease, which presents as orofacial swelling, facial palsy and fissured tongue [1]. These symptoms may occur simultaneously or, more frequently, with an oligosymptomatic or monosymptomatic pattern [2]. The histological characteristics of MRS are granulomatous infltrate constituted by epitheloid cells and multinucleate giant cells, without caseous necrosis, associated with some degree of lymphoedema and fibrosis [3]. Treatment involves systemic and/or topical corticosteroid.

We present a 4l-year old male patient with no familial and personal history of angioedema, was admitted in our department with persistant lip oedema. Dermatologic examination found lower lip edema on his face and fissure on his tongue (Fig. 1). The patient informed us about his recurrent and spontaneous facial paralysis in previous years. Cl-inhibitor (Cl-INH) deficiency was eliminated. A Melkersson-Rosenthal syndrome was confirmed by histologic findings of non caseating granulomas on lip biopsy. Corticoids were established with regression of symptoms.

\section{Consent}

The examination of the patient was conducted according to the Declaration of Helsinki principles.

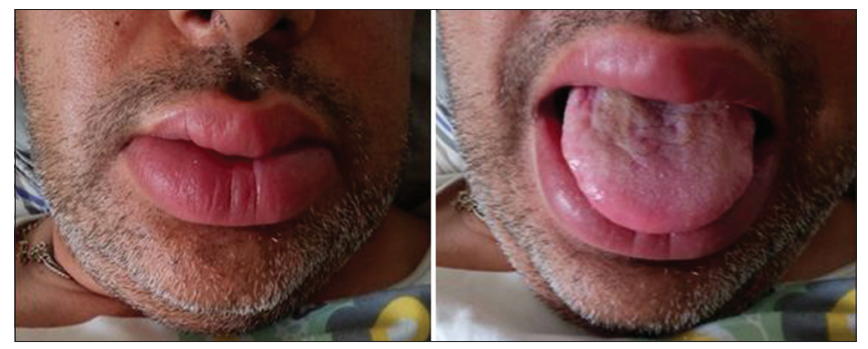

Figure 1: Lip oedema and fissured tongue.

\section{REFERENCES}

1. Kosovali B, Yavuz A, Yesiler F, Kemal Bayar M. MelkerssonRosenthal syndrome: a rare cause of recurrent facial nerve palsy and acute respiratory distress syndrome. Case Rep. Neurol Med. 2018;2018:1373581.

2. Klii R, Chebbi W. Syndrome de Melkersson-rosenthal: une entité rare à ne pas méconnaitre. Pan African Med J. 2015;21:33.

3. Cancian M, Giovannini S, Angelini A, Fedrigo M, Bendo R, Senter R, et al. Melkersson-Rosenthal syndrome: a case report of a rare disease with overlapping features. Allergy Asthma Clin Immunol. 2019;15:1.

Copyright by Taysir Ben Achour, et al. This is an open-access article distributed under the terms of the Creative Commons Attribution License, which permits unrestricted use, distribution, and reproduction in any medium, provided the original author and source are credited. Source of Support: Nil, Conflict of Interest: None declared. 